\title{
Why Economists Should Conduct Field Experiments and 14 Tips for Pulling One Off
}

\author{
John A. List
}

$\mathbf{T}$

he experimental approach has been a cornerstone of the scientific method for centuries. In one classic 1882 example, Louis Pasteur designated half of a group of 50 sheep as controls and vaccinated the other half. All animals then received a lethal dose of anthrax. Two days after inoculation, every one of the 25 control sheep were dead whereas the 25 vaccinated sheep were alive and well!

However, many economists have long been pessimistic that an experimental approach could offer such vivid illustrations of cause and effect in their field. For example, Samuelson and Nordhaus (1985) wrote in their introductory economics textbook a quarter-century ago:

The economic world is extremely complicated. There are millions of people and firms, thousands of prices and industries. One possible way of figuring out economic laws in such a setting is by controlled experiments. A controlled experiment takes place when everything else but the item under investigation is held constant. Thus a scientist trying to determine whether saccharine causes cancer in rats will hold "other things equal" and only vary the amount of saccharine. Same air, same light, same type of rat.

- John A. List is the Homer J. Livingston Professor of Economics, University of Chicago, Chicago, Illinois. He is also a Research Associate, National Bureau of Economic Research, Cambridge, Massachusetts. His email is〈jlist@uchicago.edu〉. 
Economists have no such luxury when testing economic laws. They cannot perform the controlled experiments of chemists or biologists because they cannot easily control other important factors. Like astronomers or meteorologists, they generally must be content largely to observe.

In my own travels, I have often found similar skepticism. However, such skepticism has become more muted in recent decades as experimental methods have found a foothold in economics. In fact, complications that are difficult to understand or control represent a key reason to conduct a field experiment rather than a reason for skepticism. This is because field experiments use randomization as an instrumental variable, balancing the unobserved variables across the treated and control states.

In this introduction to the symposium, I first offer an overview of the spectrum of experimental methods in economics, from laboratory experiments to the field experiments that are the subject of this symposium. I then offer some thoughts about the potential gains from doing economic research using field experiments and my own mental checklist of 14 steps to improve the chances of carrying out an economics field experiment successfully.

\section{The Spectrum of Experimentation in Economics}

Within economics, much experimental research has taken the form of laboratory experiments in which student volunteers gather in a research lab to make decisions. This work draws on the legacy of Vernon Smith, who shared the 2002 Nobel Prize in economics for, in the words of the Nobel committee, "having established laboratory experiments as a tool in empirical economic analysis, especially in the study of alternative market mechanisms" (Nobelprize.org, 2011). Work using laboratory experiments has offered a variety of insights. For example, Smith's research illustrated the robustness of market mechanisms in reaching an equilibrium price, showed the effect of institutions on allocations, and explored the formation and dissolution of asset bubbles in markets, among other lessons.

However, results in laboratory economics are inevitably subject to questions over the extent to which they generalize to non-laboratory settings. One concern is that such experiments are often done with college students as subjects. During my time in 2002-2003 at the Council of Economic Advisers, as I was urging my colleagues to take account of certain laboratory experimental results in our revisions of the Federal Benefit/Cost Guidelines, an official from the White House responded with some phrases that have been etched in my mind ever since: "even though these results appear prevalent, they are suspiciously drawn . . . by methods similar to scientific numerology . . because of students . . who are not real people."

A natural response to this concern is the "artefactual field experiment," which mimics a lab experiment except that it uses "nonstandard" subjects, in the sense that the subjects are not students, but participants drawn from the market of interest. 
Drawing from the Oxford English Dictionary, Glenn Harrison and I (2004) adopted the term "artefactual" to denote such studies-meaning that they are an empirical approach created by the experimenter that is artificial or synthetic in certain dimensions. ${ }^{1}$ In the past decade, artefactual field experiments have been fruitfully used in financial applications, public economics, environmental economics, and industrial organization, and to test predictions of game theory. In my own work, I have invited participants as varied as chief executive officers, farmers, traders from the Chicago Board of Trade and other trading outfits, as well as politicians into the laboratory for experiments. Similar work has been done more recently within development economics, where scholars have taken the laboratory tools to the field and examined behavior in a controlled setting. For instance, Henrich et al. (2005) looked at ultimatum games and dictator games in 15 different countries; Cardenas (2004) used a game that involved paying for common goods in dozens of rural communities in Colombia; and Carpenter, Daniere, and Takahashi (2004) generated data from a game that involves making contributions to a public good in Vietnam and Thailand.

Of course, a plausible concern about laboratory experiments in economics, whether the participants are students or others, is the extent to which the results are influenced by the laboratory setting. A "framed field experiment" resolves such issues by conducting a structured experiment in the natural environment of the subject rather than in the laboratory. Glenn Harrison and I denoted it "framed" because the research experiment is framed in the field context of the commodity, task, stakes, or information set of the subjects. Social experiments are a type of framed field experiment in that subjects are aware that they are taking part in an experiment and in many cases understand that their experience is for research purposes. In Europe, early social experiments included electricity pricing schemes in Great Britain in the late 1960s.

The first wave of social experiments in the United States began in earnest in the late 1960s and included government agencies' attempts to evaluate programs by deliberate variations in policies (Hausman and Wise, 1985). Other prominent social experiments include the negative income tax experiments done in four main groups across the United States in the 1970s, which looked at how labor supply responded to a gradual phase-out of welfare benefits; the RAND health insurance experiments in the 1970s, which examined how households responded to different levels of copayments and deductibles in their health insurance; the experiments with work requirements for welfare recipients in the 1980s and early 1990s; and the Moving to Opportunity experiment in the 1990s and 2000s, in which some welfare recipients were given the option of moving to nonpoverty neighborhoods. These

\footnotetext{
${ }^{1}$ In Harrison and List (2004), we classify field experiments into the categories discussed here based on six factors: the nature of the subject pool, the nature of the information that the subjects bring to the task, the nature of the commodity, the nature of the task or trading rules applied, the nature of the stakes, and the environment in which the subjects operate.
} 
experiments have had an important influence on policy and have generated much academic debate.

Framed field experiments have also been used in smaller-scale settings. Peter Bohm (1972) was an early experimenter to depart from traditional laboratory economics methods with an experiment on the willingness to pay for a public good-in this case, a highly anticipated new television show that was being broadcast on Sweden's one television station in 1969. While Bohm's work touched off an interesting stream of research within environmental and resource economics, for reasons I cannot guess, the broader economics literature did not quickly follow Bohm's lead to pursue research outside of the typical lab experiment.

More recent examples of framed field experiments within economics include my study with Jason Shogren exploring the efficacy of the contingent valuation method to estimate economic values of nonmarketed goods and services (List and Shogren, 1998); Lucking-Reiley's (1999) study testing theoretical predictions concerning various auction formats; and Fryer's (2010) study of students' responses to an experiment offering some of them financial incentives for good academic performance. More recently, the wave of field experiments or "randomized control trials" executed in developing countries are often framed field experiments, which typically are geared toward advancing policy (for example, Kremer, Miguel, and Thornton, 2009; Duflo, Dupas, Kremer, and Sinei, 2006).

Of course, a plausible concern is that when subjects know they are participating in an experiment, whether as part of an experimental group or as part of a control group, they may react to that knowledge in a way that leads to bias in the results. A "natural field experiment" occurs in the environment where the subjects are naturally undertaking certain tasks, and where the subjects do not know that they are participants in an experiment. Such an experiment combines the most attractive elements of the experimental method and naturally occurring data: randomization and realism.

By combining randomization and realism in this manner, natural field experiments provide a different parameter estimate than do laboratory, artefactual, and framed field experiments. One possible source of bias in these other experimental approaches is that generally the subjects who choose to participate in the experiment are those who expect to gain the most (perhaps because they believe they are likely to get good results from the treatment). As a result, the estimated causal effect from these other experimental types, while valid, might not generalize to the target population of interest-which of course includes the subpopulation (often the majority) that did not volunteer for the experiment when offered the opportunity.

Natural field experiments address this problem. Because subjects do not make a choice about whether they will participate, the treatment effect obtained from natural field experiments is, in the best-case scenario, an estimate that is both causal and broadly generalizable (in Al-Ubaydli and List, 2011, my coauthor and I offer a formal treatment). Put simply, since participants in the natural field experiment are a representative, randomly chosen, non-self-selected subset of the treatment population of interest, the causal effect obtained from this type of experiment is 
the average causal effect for the full population-not for a nonrandom subset that choose to participate.

Natural field experiments have recently been used to answer a wide range of questions in economics. By now, natural field experiments have touched nearly every subfield of economics. Papers in this symposium reveal how they have affected our understanding of theories in labor economics as well as in industrial economics. In List (2006a), I review a broader set of my own natural field experiments that have: 1) explored the economics of charity, 2) extended Vernon Smith's seminal work to explore market mechanisms in the field, 3) measured preferences to advance our knowledge of issues ranging from benefit-cost analysis to why people discriminate in markets, and 4) provided a means to test the implications of behavioral and neoclassical theories.

Natural field experiments have addressed many other areas as well. More recent examples of clever natural field experiments include those of Karlan and Zinman (2009), who use variations in how credit is provided in a developing country context to explore tenets of principal-agent theory. Using door-to-door salespeople in Zambia, Ashraf, Berry, and Shapiro (2010) explore how product pricing affects not only the quantity purchased, but also whether the product is ultimately used by the consumer. Finally, Hossain and Morgan (2006) use an Internet natural field experiment to examine how treatment of shipping and handling charges affects on-line shopping.

Although my discussion in this section divides experimental studies according to whether they are artefactual, framed, or natural field experiments, these lines can become blurred. Indeed, in List (2004), I present a series of field experiments—from artefactual to framed to natural-in an actual marketplace to provide an empirical framework for disentangling the animus and statistical theories of discrimination. In some cases, comparing behavior across different kinds of field experiments permits crisp insights into whether behavior is different across the lab and the field, and why such differences exist. In List (2006b), I used a similar approach, parsing the roles of gift exchange and strategic reciprocity in markets to explore whether, and to what extent, fairness concerns affect actual market transactions.

Over the past decade or so, field experiments in economics have matured to the point that they now readily 1 ) measure key parameters to test theory and, when the theory is rejected, provide information to inform a new theory; 2) extend to both nonprofit and for-profit firms; 3) aid in bridging laboratory and nonexperimental data; and 4) inform policymakers. A snapshot of this work is cited and discussed in the three papers in this symposium.

\section{What Happened to Informed Consent?}

What issues arise when experimenting with subjects who do not know that they are part of an experiment? I have discussed this issue elsewhere-List (2008) and Levitt and List (2009) - but it is worth briefly summarizing some of those 
thoughts here. The Nuremberg Code of 1947 was created as a way to prevent the sorts of immoral experiments conducted by Nazi doctors during World War II. One of the principle protections devised for participants in studies was voluntary consent. Voluntary consent required that subjects i) are physically able to provide consent, ii) are free from coercion, and iii) can comprehend the risks and benefits involved in the experiment. In experiments that can affect the physical health of the participants, voluntary consent remains essential. However, the case for voluntary consent in economic experiments is less clear-cut.

For example, consider a study that attempts to measure racism by sending people of different races but otherwise similar appearance to car dealers and then observing the prices that car dealers offer. The car dealer suffers no physical injury from participating in this experiment; indeed, the dealer may forever be unaware of having participated. Moreover, if the car dealer were aware of the experiment, that could quite possibly lead to different behavior. In a number of situations, behavior often changes when people know they are being observed (Homan, 1991). Clearly, natural field experiments should be subject to clear-cut and severe ethical oversight. In U.S. colleges and universities, there are often Local Research Ethics Committees and Institutional Review Boards to serve as effective advocates for the rights of subjects. With the benefit of such oversight, there are valid arguments for not making informed consent an ironclad rule in natural field experiments. That said, the costs and benefits of covert experimentation is not a settled issue and the interested reader should see Dingwall (1980) and Punch (1985).

\section{The Promise of Field Experiments in Economics}

The empirical gold standard in the social sciences is to estimate a causal effect of some action, but amidst the complexity of the real world, this is easier said than done. Economists have long worked on approaches that seek to separate cause and effect in naturally occurring data. A few decades ago, a standard approach was to use multiple regression analysis in an attempt to hold other factors constant. But economists have now taken to heart the old maxim that "correlation doesn't imply causation," and have in recent decades sought out a variety of other approaches.

For example, the instrumental variables approach seeks out a sometimes unexpected source of exogenous variation to disentangle cause and effect. "Natural experiments" seek out an event or a change in the law that arguably creates exogenous variation in the variable of interest. One typically analyzes changes in a population that received the variation compared with changes in another population that didn't, under the assumption that they would have experienced much the same change in the absence of the treatment. A regression discontinuity approach looks for a situation where those immediately above the level of a certain characteristic-perhaps age or income-are treated differently than those just below that level, and then, based on the assumption that those barely above the defining line are not that different than those barely below the line, looks for 
whether a discontinuity occurs. Structural modeling can be a powerful approach to guide empirical regressions. It's possible to evaluate treatment programs not by experimental methods, but by making a statistical adjustment for those who are in the program compared with those outside the program, using the method of propensity score matching (Rosenbaum and Rubin, 1983).

All of these approaches of modeling naturally occurring data, along with others not mentioned here, are quite useful. I do not come to bury econometric studies based on nonexperimental data, but rather to praise them. As I have argued for over a decade, my strong belief is that field experiments can usefully complement studies based on naturally occurring data and lab data. In this way, field experiments offer another useful set of arrows for the quiver of empirically minded economists. When combined with theory, field experiments represent an important and undervalued approach to further our understanding of economics.

To be sure, we must work carefully when drawing conclusions based on the results of field experiments. Was the selection of participants into the treatment and experimental groups truly random? Do those who are not treated take some action as a result of being in the experiment, albeit in the control group, that they might not otherwise have taken? Is there something about the population being studied-perhaps risk-tolerance or persistence or belief that the treatment worksthat warrants caution in generalizing the results to other populations? In the last few years, a lively literature has debated these and other issues that can arise in field experiments. The reader interested in these debates might begin with Heckman and Smith (1995) and Deaton (2010), who focus their criticisms largely on framed field experiments.

The papers in this symposium offer a wide sampling of field experimental work in economics as it has been evolving. Along the way, these papers show how researchers are seeking practical ways to address many of these potential concerns. In "Mechanism Experiments and Policy Evaluations," Jens Ludwig, Jeffrey R. Kling, and Sendhil Mullainathan discuss how we can learn from doing field experiments in complex policy environments. They emphasize the importance of uncovering the mechanism through which a treatment effect actually occurs-an insight that in many cases can be derived from a relatively simple set of field experimental treatments. In "The Role of Theory in Field Experiments," David Card, Stefano DellaVigna, and Ulrike Malmendier propose a way of classifying experimental studies according to the ways in which they are linked to economic theory, and they provide evidence that as field experiments have become more prominent in top economics journals, so have explicit theoretical foundations for those experiments. In "Field Experiments with Firms," Oriana Bandiera, Iwan Barankay, and Imran Rasul show how field experiments can illuminate a variety of firm decisions about methods of employee compensation and competitive strategy. Reading their paper, I was struck by how much of the modern-day business school curriculum might usefully be explored with the judicious use of field experiments.

Along with their many specific lessons, these three papers illustrate the general advantages of field experiments. First, field experiments offer a distinctive and new 
source of empirical evidence, which can then be compared, contrasted, reconciled, and eventually intertwined with evidence from nonexperimental and lab methods. Admittedly, this new experimental evidence will bring its own methodological challenges, but when the field experiments are well-designed and rooted in economic theory, their evidence also has some distinctive strengths. Second, field experiments offer an immediate opportunity to specify and address the economic question of interest, rather than waiting and hoping for a natural event or a cast-iron econometric specification that would allow the researcher to address the issue cleanly. Consequently, conducting successful field experiments demands a different set of skills from traditional economic research, including the ability to recognize opportunities for experimentation hidden amidst everyday phenomena, an understanding of experimental design, and the interpersonal skills to manage what are often a complex set of relationships involving parties to an experiment. Finally, field experiments offer economists the possibility of an improved connection from economic theory and empirical evidence to the real world, built on a deeper contextual understanding of real-world issues and institutions.

\section{How Do I Get Started?}

The idea of carrying out a field experiment may seem daunting. It means visiting a market or a firm that you may not know well, introducing yourself, and figuring out how to randomize important economic variables within a possibly complex situation. You must brace yourself for possible pitfalls along the way. Here, I offer 14 tips for improving your chances of executing successful field experiments.

\section{Use economic theory to guide your design and as a lens to interpret your findings.}

Economic theory is portable; empirical results in isolation offer only limited information about what is likely to happen in a new setting. Together, however, theory and experimental results provide a powerful guide to situations heretofore unexplored. Experimental results are most generalizable when they are built on tests of economic theory.

\section{Be an expert about the market that you are studying.}

This is perhaps the most important insight that I have gained over my nearly 20 years of running field experiments. As a sports card dealer running natural field experiments in the early 1990s, I needed to understand the inner workings of the market-to have detailed knowledge of the underlying motivations of the actors in the market: buyers, sellers, third-party certifiers, and organizers. My past experience with this market was quite beneficial in crafting designs in which the incentives would be understood and interpreted correctly, and also in generating alternative hypotheses and understanding how to interpret the experimental data. 


\section{Have a proper control group.}

Experimentation is ubiquitous. Wherever I go to set up research-across profit and nonprofit firms, federal and local government agencies, school districts, Chinese manufacturing plants, and trading pits-I see that everyone already experiments. Unfortunately, what is common across all of these venues is that the experimenter rarely has a proper control group to compare results with the treated group. In nearly all cases, the comparison or control group is ill-conceived-past behavioral patterns or current behavioral patterns from a different population are used as a control group. Doing this is like neutering homo experimentalis.

\section{Obtain sufficient sample sizes.}

One prominent reason why field experiments fail is that they were ill-powered from the beginning. This stems from the fact that experimentalists do not pay enough attention to the power of the experimental design-whether it be that clustering was not accounted for or other potential nuances were ignored. Indeed, beyond that, one of the first questions I am always asked when I meet to obtain an initial agreement to run a field experiment is: "How many people do we need for the experiment?" To respond, "It depends on the variance of the sample," is inappropriate. Rather, you should place sample sizes in the language of standardized effect sizes. For example, I tell the local school superintendant that if we want to detect a quarter of a standard deviation treatment effect, we need 256 observations in treatment and 256 in control. Of course, the superintendant does not typically understand what a quarter of a standard deviation is, so I complement that statement with something along the lines of "That is in the neighborhood of one-half of the black/white achievement gap."

\section{Have a champion within the organization - the higher up the better.}

Making the experiment a "we" project instead of an "us versus them" pursuit as early as possible is critical. This may be the most important element to having a field experiment actually completed. Within firms, having the chief executive officer behind the research is optimal; if the chief executive officer is not your champion, then try to obtain the help of the chief information officer, chief strategy officer, or a comparable person. Within school districts, the superintendant or at least the school principal must be at your side. You may not get much in-person help from these champions; the point is, they have the wherewithal to make others in the organization more likely to help.

\section{Understand organizational dynamics.}

In every venue that I have worked, someone seemingly was put there to halt my efforts. I call this the "Adam" effect because in two firms, my nemesis was actually named Adam! This person, who is typically smart but insecure, will key in on potential vulnerabilities and will attempt to thwart your efforts at every turn. I have found that in just about every case, it is better to be collegial and seek to turn this person to your side rather than buck horns continuously. Insiders always have a way 
to stop your field experiment or to make it so costly that you will want to halt the experiment yourself.

\section{Organizations that have "skin in the game" are more likely to execute your design and use your results to further organizational objectives.}

One interesting feature of field experiments is that when the organization has invested resources-even if they are sunk costs-the organization is more likely to complete the project. This spills over to how they use your results afterwards, too. I have found, across firms and agencies, that my results are more likely to be considered useful and implemented if the organization has invested resources to help execute the experiment. I suspect this result is not because the research is "better" in some way due to the resource investment of the organization. Perhaps the organization believes the results are more "trustworthy" or they must make use of them because they have paid to obtain the information.

\section{Run the field experiment yesterday rather than tomorrow.}

My curriculum vitae would double in length if I could turn back the clock and execute all my planned field experiments two weeks before their planned execution. Sometimes, there are the "cold feet" cancellations. In other cases, the field experiment is cancelled because the chief executive officer is fired, your project manager is shipped to the Venezuelan office, your insider goes on personal leave because his wife becomes ill, or a nemesis finally succeeds in sabotaging your efforts.

\section{Change the nature of the discussion of the cost of the experiment.}

An aspect of potential field experiments salient to partners is the burden of their cost. After the query concerning sample sizes, the next question will concern cost-Adam will be sure to mention it. Your task is to enlighten such efforts with basic economic arguments. For instance, when a nemesis claims that this experiment will cost the firm too much money, I often respond that we are "costing" the firm too much money by not experimenting. Every minute that passes wherein the organization does not know the elasticity of demand, whether its ads are really working, or the effectiveness of dollars spent on teacher resources, is money lost. When an organization understands the opportunity cost of time-of not yet using field experiments to maximize feedback-you have effectively reversed the cost argument in your favor. Indeed, in many cases I have worked on, there was actually a prospect of making money during the experiment and so producing a double dividend.

\section{Make clear that you do not have all the answers.}

You typically gain entrance into an organization because it is having problems. People in organizations know that they are facing problems, and they may not welcome an outsider-especially one who claims to arrive with all of the answers. And of course, economists often do not have the correct answers to the organization's most pressing challenges. Admitting this up front, while adding that you have 
the tools to learn about the answers in a partnership with them, goes a long way towards ensuring long-term success. For example, within education circles, I readily admit that I do not know the education production function; but I emphasize that I have tools that will help us discover aspects of it.

\section{Be open to running experiments that might not provide high-powered research findings in the short run.}

Organizations are often wary of giving an economist carte blanche to randomize some variable of interest-and justifiably so! Sometimes getting your foot in the door by conducting experiments that are not intellectually satisfying can lay the groundwork for much more intellectually interesting exogenous variation in the future. In this way, the original experiments represent a long-term investment in building the trust of the organization.

\section{Don't be captured by the organization.}

Of course, tip no. 11 can be pushed too far. An organization may wish to focus on experiments that have a high private return to the organization, but a lower social return for the research community. To do so, it may seek to limit the number of interesting treatments that can be employed. In addition, it may wish to have the power to block publication of certain findings-especially findings that support a negative interpretation of some kind. These issues are rarely black-and-white, and there is often some room for compromise between the agendas of the researcher and the organization. But independent researchers will also have to define for themselves the lines that should not be crossed so their research goals are not overly limited by the organization.

\section{Understand fairness concerns.}

As my field experimental work has taken me deeper into the public policy world, I am more often met with fairness concerns. The line of argument is that it is not fair to only give a fraction of the population a potentially beneficial treatment. While I am sympathetic to this line of reasoning, it is ultimately flawed. First of all, it only considers contemporaneous trade-offs. One could easily argue that it is not fair to future generations to bypass learning opportunities that could make them better off. I am personally glad that earlier generations executed experiments to determine the efficacy of promising drugs so that today my father's heart condition can be treated appropriately. Second, even if one insists on everyone receiving treatment, it remains possible to execute an experiment whereby people receive treatment in waves over time.

\section{Always obtain IRB approval.}

Local Research Ethics Committees and Institutional Review Boards (IRBs) in the United States serve an important role in monitoring experimental research. Before commencing a field experiment, you should be sure to receive IRB approval. Some researchers do not have Local Research Ethics Committees and 
Institutional Review Boards. Outside the United States, for example, researchers in the social sciences must rely largely on their own principles. In those cases, I urge the researcher to follow, as closely as possible, strict guidelines that protect the rights of experimental subjects.

\section{Conclusion}

When economists are struggling to understand a key causal connection or an important structural parameter or the effects of a change in business practice or public policy, they have long used this semiautomatic approach: write down a theoretical model and start looking for available naturally occurring data. To economists, "field research" has often meant chatting with the cab driver on the way from the airport to another academic seminar. But more and more empirical economists are opening their eyes and searching for situations and questions in which a field experiment might offer a feasible and desirable approach.

As I have noted elsewhere, field experiments represent a unique manner in which to obtain data because they force the researcher to understand everyday phenomena, many of which we stumble upon frequently. Merely grasping the interrelationships of factors in field settings is not enough, however, as the field experimenter must then seek to understand more distant phenomena that have the same underlying structure. Until this is achieved, one cannot reap the true rewards of field experimentation. I hope that this symposium furthers economists' usage of the field experimental method.

- I thank Alec Brandon for excellent research assistance. The other JEP editors provided astute comments that improved the paper, as did David Herberich, Kelsey Jack, Botond Koszegi, Jeffrey Livingston, Sally Sadoff, and Anya Savikhin.

\section{References}

Al-Ubaydli, Omar, and John A. List. 2011. "On the Generalizability of Experimental Results in Economics." Unpublished paper, University of Chicago.

Ashraf, Nava, James Berry, and Jesse M. Shapiro. 2010 "Can Higher Prices Stimulate Product Use? Evidence from a Field Experiment in Zambia." American Economic Review, 100(5):
2383-2413.

Bohm, Peter. 1972. "Estimating the Demand for Public Goods: An Experiment." European Economic Review, 3(2): 111-130.

Cardenas, Juan-Camilo. 2004. "Norms from Outside and from Inside: An Experimental Analysis on the Governance of Local Ecosystems. Forest Policy and Economics, vol. 6, pp. 229-41. 
Carpenter, Jeffrey, Amrita G. Daniere, and Lois M. Takahashi. 2004. "Cooperation, Trust, and Social Capital in Southeast Asian Urban Slums." Journal of Economic Behavior and Organization, 55(4): 533-51.

Deaton, Angus. 2010. "Understanding the Mechanisms of Economic Development." Journal of Economic Perspectives, 24(3): 3-16.

Dingwall, Robert. 1980. "Ethics and Ethnography." Sociological Review, 28(4): 871-91.

Duflo, Esther, Pascaline Dupas, Michael Kremer, and Samuel Sinei. 2006. "Education and HIV/AIDS Prevention: Evidence from a Randomized Evaluation in Western Kenya." Policy Research Working Paper 4024, World Bank.

Fryer, Roland G. 2010. "Financial Incentives and Student Achievement: Evidence from Randomized Trials." http://www.edlabs.harvard .edu/pdf/studentincentives.pdf.

-Harrison, Glenn W., and John A. List. 2004. "Field Experiments." Journal of Economic Literature, 42(4): 1009-55.

Hausman, Jerry A., and David A. Wise, eds. 1985. Social Experimentation. Chicago: University of Chicago Press for National Bureau of Economic Research, pp. 1-55.

Heckman, James J., and Jeffrey A. Smith. 1995. "Assessing the Case for Social Experiments." Journal of Economic Perspectives, 9(2): 85-110.

Henrich, Joseph, et al. 2005. "Economic Man' in Cross-Cultural Perspective: Behavioral Experiments in 15 Small-Scale Societies." Behavioral and Brain Sciences, 28(6): 795-815.

Homan, Roger. 1991. The Ethics of Social Research. Longman: London.

Hossain, Tanjim, and John Morgan. 2006. “.. . Plus Shipping and Handling: Revenue (Non) Equivalence in Field Experiments on eBay." Advances in Economic Analysis and Policy, 6(2): Article 3.

Karlan, Dean, and Jonathan Zinman. 2009. "Observing Unobservables: Identifying Information Asymmetries with a Consumer Credit Field Experiment.” Econometrica, 77(6): 1993-2008.
Kremer, Michael, Edward Miguel, and Rebecca Thornton. 2009. "Incentives to Learn." Review of Economics and Statistics, 91(3): 437-56.

-Levitt, Steven D., and List, John A. 2009 "Field Experiments in Economics: The Past, the Present, and the Future." European Economic Review, 53(1): $1-18$.

List, John A. 2004. "The Nature and Extent of Discrimination in the Marketplace: Evidence from the Field." Quarterly Journal of Economics, 119(1): 49-89.

List, John A. 2006a. "Field Experiments: A Bridge between Lab and Naturally Occurring Data." The B.E. Journal of Economic Analysis and Policy, 6(2): Article 8.

List, John A. 2006b. "The Behavioralist Meets the Market: Measuring Social Preferences and Reputation Effects in Actual Transactions." Journal of Political Economy, 114(1): 1-37.

List, John A. 2008. "Informed Consent in Social Science." Science, 322(5886): 672.

List, John A., and Jason Shogren. 1998. "Calibration of the Difference between Actual and Hypothetical Reported Valuations." Journal of Economic Behavior and Organization, 37(2): 193-205.

-Lucking-Reiley, David, 1999. "Using Field Experiments to Test Equivalence between Auction Formats: Magic on the Internet." American Economic Review, 89(5): 1063-80.

Nobelprize.org. 2011. "The Sveriges Riksbank Prize in Economic Sciences in Memory of Alfred Nobel 2002: Daniel Kahneman, Vernon L. Smith" Webpage. http://nobelprize.org /nobel_prizes/economics/laureates/2002 / (accessed 6/27/2011).

Punch, Maurice. 1985. The Politics and Ethics of Fieldwork. Sage: London.

Rosenbaum, Paul R., and Donald B. Rubin. 1983. "The Central Role of the Propensity Score in Observational Studies for Causal Effects." Biometrika,70(1): 41-55.

Samuelson, Paul A., and William D. Nordhaus. 1985. Economics, $12^{\text {th }}$ ed. New York: McGraw-Hill. 
16 Journal of Economic Perspectives 